\title{
Avaliação do desenvolvimento do capim Tifton cultivado em latossolo adubado com lodo de ETA
}

\author{
Ana Carolina de Souza Ferreira '; Jonathas Batista Gonçalves Silva '; Renata de Oliveira Pereira '; \\ Adriana Paulo de Sousa Oliveira ${ }^{2}$ \\ $\triangle$ carolinasouza_1991@hotmal.com \\ 1. Universidade Federal de Juiz de Fora, Faculdade de Engenharia - Campus da UFJF, 4a Plataforma do Setor de Tecnologia, Juiz \\ de Fora, Brasil. \\ 2. Universidade Federal Rural do Rio de Janeiro, Instituto de Tecnologia / Departamento de Engenharia \\ Rodovia Br 465, Km 7, Seropédica, Brasil.
}

Histórico do Artigo:

Recebido: 24 de novembro de 2016

Aceito: 14 de junho de 2017

Publicado: 18 de julho de 2017

\begin{abstract}
Resumo: 0 tratamento da água gera grandes quantidades de lodo, que se origina nos decantadores e filtros das estações de tratamento de água (ETAs). Dentre algumas alternativas de disposição final deste resíduo, destacamse 0 aterro sanitário, aplicação em áreas agrícolas, fabricação de cimento e tijolos e compostagem. Diante do exposto, o trabalho teve por objetivo avaliar o desenvolvimento do capim Tifton (Cynodon spp. cv) cultivado em um Latossolo Vermelho-Amarelo adubado com lodo de ETA. A pesquisa foi conduzida na universidade federal de Juiz de Fora, no município de Juiz de Fora - MG e avaliou a aplicação de distintas doses de lodo de ETA em relação às características de crescimento, produção de massa seca e acúmulo de nutrientes da parte aérea e radicular de dois ciclos consecutivos de 45 dias cada. Os tratamentos avaliados foram T0, T1, T2, T3 e T4 que receberam 0; 1,36; 2,73; 4,09 e 5,45 $\mathrm{Kg} \mathrm{m}^{-2}$, respectivamente, de lodo de ETA. 0 experimento foi conduzido em delineamento inteiramente casualizado, cada tratamento com quatro repetições, totalizando 20 unidades experimentais. A aplicação dos tratamentos resultou em uma baixa produtividade e sintomas de toxidade por manganês e ferro. Concluiu-se com base nos resultados que o lodo de ETA não apresentou potencial agronômico.
\end{abstract}

Palavras-chave: Disposição final, Potencial Agronômico, Resíduo Sólido.

\section{Assessment of Tifton grass development in latosol fertilized with WTS sludge}

\begin{abstract}
The water treatment generates large amounts of sludge, which originates in the clarifiers and filters at the water treatment stations (WTS). Among some alternative of the final disposal of this waste, it stands out the landfill, application in agriculture, cement and bricks manufacturing and composting. At this point of view of what has been exposed, this study aimed to evaluate the development of Tifton grass (Cynodon spp. cv) grown in an redyellowed latosol fertilized with WTS sludge. The study was conducted at Juiz de Fora Federal University in Juiz de Fora - MG and assessed the application of different WTS sludge doses with growth characteristics, dry matter yield and nutrients accumulation of the roof and above the ground parts of two consecutive cycles, having 45 days each. The assessed treatments were T0, T1, T2, T3 and T4 receiving WTS sludge 0; 1.36; 2.73; 4.09 and 5.45 kg m ${ }^{2}$, respectively. The experiment was conducted in a completely randomized design, each treatment with four replications, in a total of 20 experimental units. The application of the treatments resulted in low productivity and symptoms of toxicity due to manganese and iron. It was concluded, based on the results that the sludge did not present agronomic potential.
\end{abstract}

Keywords: Final Disposal, Agronomic Potential, Solid Waste. 

ETA

\title{
Evaluación del desarrollo del capim Tifton cultivado en latosolo abonado con lodo de ETA
}

\begin{abstract}
Resumen: El tratamiento del agua genera grandes cantidades de lodo, que se origina en los decantadores y filtros de las estaciones de tratamiento de aguas (ETA). Entre algunas alternativas de disposición final de este residuo, se destacan el relleno sanitario, aplicación en áreas agrícolas, fabricación de cemento y ladrillos y compostaje. Ante el expuesto, el trabajo tuvo como objetivo evaluar el desarrollo del pasto Tifton (Cynodon spp. cv) cultivado en un Latosol Rojo-Amarillo abonado con lodo de ETA. La investigación fue conducida en la universidad federal de Juiz de Fora, en el municipio de Juiz de Fora - MG y evaluó la aplicación de distintas dosis de lodo de ETA en relación a las características de crecimiento, producción de masa seca y acumulación de nutrientes de la parte aérea y radicular de dos ciclos consecutivos de 45 días cada uno. Los tratamientos evaluados fueron T0, T1, T2, T3 y T4 que recibieron $0 ; 1,36 ; 2,73 ; 4,09$ y 5,45 $\mathrm{Kg} \mathrm{m}^{-2}$, respectivamente, de lodo de ETA. El experimento fue conducido en delineamiento completamente casualizado, cada tratamiento con cuatro repeticiones, totalizando 20 unidades experimentales. La aplicación de los tratamientos resultó en una baja productividad y síntomas de toxicidad por manganeso y hierro. Se concluyó con base en los resultados que el lodo de ETA no presentó potencial agronómico. Palabras clave: Disposición Final, Potencial Agronómico, Residuo Sólido.
\end{abstract}

\section{INTRODUÇÃ0}

0 constante processo de urbanização ocasiona mudanças nos hábitos dos indivíduos gerando crescente consumo de água per capita e industrial, além da degradação da qualidade da mesma. 0 tratamento da água gera grandes quantidades de resíduos, com destaque o lodo de estação de tratamento de água (LETA), que se origina nos decantadores e filtros das estações de tratamento de água (ETA) (PROSAB, 1999).

No Brasil, 62 \% dos resíduos das ETAs são frequentemente dispostos em cursos d'água sem qualquer tratamento e apenas 5,9\% tem algum tipo de destinação adequada como aterro sanitário, reaproveitamento e incineração (IBGE, 2010).

Este método de disposição em curso d'água sem tratamento tem sido restringido e até proibido pelas regulamentações sobre prevenção ou recuperação da qualidade do meio ambiente. Uma vez que, o LETA é classificado como resíduo sólido, de acordo com a norma técnica NBR10004 (2004) e deve ser tratado e disposto adequadamente (DI BERNARD0 e SAB0GAL, 2008). Esta disposição inadequada em corpos hídricos pode alterar as características do corpo receptor como o assoreamento do corpo d' água, produção de odores, crescimento excessivo de algas e morte de peixes, além de causar danos à vida aquática e à saúde pública (TSUTIYA e HIRATA, 2001; RAMALHO, 2015). 
As restrições legais e os altos custos associados ao tratamento e transporte do LETA, visando a sua disposição final, têm levado à busca de soluções mais econômicas e com responsabilidades ambientais (TSUTIYA e HIRATA 2001; RICHTER, 2001).

Algumas alternativas de disposição final adequadas para LETA são descritas por diversos autores, Tsutiya e Hirata (2001) referenciam a disposição em aterro sanitário, cultivo de grama comercial e plantas cítricas, fabricação de cimento e tijolos, compostagem e utilização em indústrias cerâmicas. 0 uso como aditivo no setor agrícola e de construção civil, além de aplicação em indústrias diversas, é sugerido por Richter (2001) e Botero et al. (2009). Além dessas, a aplicação do LETA em solos agrícolas é uma promissora alternativa, uma vez que apresenta, melhoria da estrutura do solo, ajuste de pH aumento da capacidade de retenção de água e condições de aeração do solo, devido ao aumento de números de poros. Além de conter em sua composição macro e micro nutrientes essenciais as plantas, substâncias similares às encontradas no solo e ter baixo risco de contaminação ambiental (RAMALH0, 2015; MACHAD0, 2005; RICHTER, 2001). Para tal, devem-se determinar as características do LETA e a exigência nutricional das culturas a serem cultivadas.

0 lodo de ETA tem características variáveis de acordo com as características da água antes do tratamento e da sequência dos processos de tratamento (LIBÂNIO, 2008; TSUTIYA e HIRATA, 2001). De forma geral o lodo de ETA é composto dos resíduos sólidos orgânicos e inorgânicos provenientes da água bruta, elementos químicos dissolvidos como cálcio, magnésio, ferro e manganês acrescido dos produtos químicos utilizados no tratamento da água, principalmente os coagulantes (RICHTER, 2001). As ETAs que utilizam sulfato de alumínio como coagulante geram lodos com menor potencial agrícola, uma vez que o alumínio além de ser tóxico, não apresenta nenhuma função para o desenvolvimento das plantas. Assim para que 0 lodo seja utilizado como aditivo agrícola é pertinente à utilização de outro coagulante, tal como 0 cloreto férrico.

A disposição do lodo em pastagem torna-se uma alternativa interessante. Segundo Guimarães (2012) a pastagem é o principal alimento de rebanho no Brasil. Consequentemente, as pastagens ocupam grande parte das áreas agricultáveis. 0 capim Tifton 85 é uma gramínea forrageira de clima tropical e subtropical e constitui uma alternativa bastante viável na alimentação animal, dado ao seu alto potencial de produção, fácil cultivo, baixo custo e por ser fonte de nutrientes para os animais em pastejo (SARMENT0 et al., 2006). 
Avaliação do desenvolvimento do capim Tifton cultivado em latossolo adubado com lodo de ETA

Seguindo tais pressupostos, objetivou-se neste trabalho avaliar o uso ambientalmente correto da disposição do lodo de ETA no solo e seu potencial agronômico no cultivo do capim Tifton 85.

\section{MATERIAL E MÉTODOS}

Esta pesquisa é continuidade ao trabalho realizado por Oliveira et al. (2015) que objetivou avaliar as propriedades químicas e físicas de um latossolo após aplicação do lodo originado nos decantadores de uma ETA.

Este trabalho foi realizado na Universidade Federal de Juiz de Fora (UFJF), situada no município de Juiz de Fora, Minas Gerais, entre março de 2015 e março de 2016. 0 município está situado à $21^{\circ} 41^{\prime} 20^{\prime \prime}$ Sul e $43^{\circ} 20^{\prime} 40^{\prime \prime}$ Oeste, com uma área territorial de $1435 \mathrm{~km}^{2}$ e uma população de 555 mil habitantes (IBGE,2015). Segundo os dados da Normal Climatológica do Brasil, 1961-1990, o município apresenta temperatura média de $19,3{ }^{\circ} \mathrm{C}$, temperatura média mínima igual a $15,4^{\circ} \mathrm{C}$, temperatura média máxima igual a $25,1^{\circ} \mathrm{C}$ e precipitação total de 1597,00 mm (INMET, 1992). 0 clima da região é o Clima Tropical de Altitude, de acordo com a classificação de W. Köppen, a região possui um clima Cwa, ou seja, um clima mesotérmico com verões quentes e chuvosos.

0 lodo de ETA foi obtido de decantadores de uma ETA localizada no município de Juiz de Fora/MG. A ETA possui tratamento convencional e trata a água do Ribeirão Espírito Santo usando cal para correção de pH e FLOCULAN (sulfato ferroso clorado [FeCl3xFe2(S04)3]), como coagulante, produzindo aproximadamente 620 Ls-1 de água tratada e abastecendo 40\% da população do município (CESAMA, 2016; ASSIS, 2014). Segundo Oliveira et al.(2015) a ETA opera com dois decantadores de aproximadamente $1.609 \mathrm{~m}^{3}$ cada, que são lavados manualmente aproximadamente a cada 60 dias.

0 lodo de ETA do trabalho foi o mesmo caracterizado por Oliveira et al.(2015), coletado em agosto de 2014, em pontos variados dos decantadores da ETA. A caracterização, na Tabela 1, consistiu da análise da determinação de nutrientes como Cálcio, Fósforo, Potássio, Enxofre e de metais como Manganês, Ferro, Zinco, Cromo, Níquel, Cádmio, Chumbo, Boro além de parâmetros como matéria orgânica e poder neutralizante, conforme método estabelecido por EMBRAPA (2011). 
Tabela 1 - Caracterização do lodo de decantador da ETA convencional do município de Juiz de Fora, MG

\begin{tabular}{cr|cr|cr}
\hline \multicolumn{2}{c|}{$\begin{array}{c}\text { Parâmetros } \\
\left(\mathbf{g ~ k g ~}^{-1}\right)\end{array}$} & \multicolumn{2}{c|}{$\begin{array}{c}\text { Parâmetros } \\
\left(\mathbf{g ~ k g}^{-1}\right)\end{array}$} & \multicolumn{2}{c}{$\begin{array}{c}\text { Parâmetros } \\
\left(\mathbf{g ~ k g}^{-1}\right)\end{array}$} \\
\hline $\mathrm{Ca}$ & 51,9 & $\mathrm{Fe}$ & 321,1 & $\mathrm{~Pb}$ & 6,4 \\
$\mathrm{Mg}$ & 32,1 & $\mathrm{Zn}$ & 155,3 & $\mathrm{Ni}$ & 71,5 \\
$\mathrm{~N}$ & 21 & $\mathrm{Mn}$ & 525,9 & $\mathrm{~B}$ & 3,1 \\
$\mathrm{P}$ & 22,9 & $\mathrm{Cu}$ & 37,5 & $\mathrm{~S}$ & 2,5 \\
$\mathrm{~K}$ & 14,6 & $\mathrm{Cd}$ & 11,2 & $\mathrm{PN}$ & \\
$\mathrm{M} 0^{(1)}$ & 401 & $\mathrm{Cr}$ & 105,5 & & 1,2 \\
\hline
\end{tabular}

(1) Matéria Orgânica; (2) Poder Neutralizante (\%).

Fonte: Oliveira et al. 2015.

0 solo utilizado foi um Latossolo Vermelho-Amarelo coletado em uma área de plantio de Eucalipto no município de Silveirânia, Minas Gerais (MAPA DE SOLOS D0 ESTADO DE MINAS GERAIS, 2010). Coletado em 25 pontos de amostragem, com profundidade de $20 \mathrm{~cm}$ e acondicionado em sacos de $2 \mathrm{~kg}$. As amostras foram misturadas e secadas a sombra (OLIVEIRA, 2015). Após está homogeneização, para cada tratamento, o solo foi separado em um recipiente e misturado com dosagem de LETA referente ao tratamento. As doses de LETA foram definidas considerando o nitrogênio como elemento de referência. Assim, adotaram-se as seguintes proporções de LETA: 0\%, 50\%, 100\%, 150\% e 200\% em relação à dose calculada por Oliveira et al. (2015). Posteriormente, embalagens de muda de polietileno de 3L (diâmetro médio 0,1 m) foram preenchidas com brita zero no fundo e a mistura solo-LETA.

Estabeleceu-se desta forma os tratamentos adotados em relação às distintas doses de aplicação do lodo de cada parcela experimental, observado na Tabela 2. 
Avaliação do desenvolvimento do capim Tifton cultivado em latossolo adubado com lodo de ETA

Tabela 2 - Tratamentos em função da dose de aplicação do LETA

\begin{tabular}{cccc}
\hline \multirow{2}{*}{ Tratamentos } & \multicolumn{2}{c}{ Proporção da $\mathrm{D}_{\text {res }}{ }^{(1)}$} & \multicolumn{2}{c}{ Taxa de Aplicação de N } \\
\cline { 2 - 4 } & $(\mathbf{\%})$ & $\left(\mathrm{Kg} \mathrm{m}^{-2}\right)$ & $\left(\mathrm{Kg} \mathrm{ha}^{-1}\right)$ \\
\hline T0 & 0 & 0 & 0 \\
T1 & 50 & 1,36 & 13600 \\
T2 & 100 & 2,73 & 27300 \\
T3 & 150 & 4,09 & 40900 \\
T4 & 200 & 5,45 & 54500 \\
\hline
\end{tabular}

(1)Dres refere-se a dose de resíduo (Lodo de ETA).

Fonte: Oliveira et al. 2015.

Na Tabela 3 apresentam-se as características do solo após a incorporação e incubação do LETA.

Tabela 3 - Caracterização do solo após adubação para os diferentes tratamentos

\begin{tabular}{|c|c|c|c|c|c|c|}
\hline $\mathrm{P}^{(1)}$ & Unidade & $\mathrm{T} 0^{(9)}$ & $\mathrm{T1}^{(9)}$ & $\mathrm{T} 2^{(9)}$ & $\mathrm{T} 3^{(9)}$ & $\mathrm{T} 4^{(9)}$ \\
\hline $\mathrm{pH}$ & $\mathrm{em} \mathrm{H}_{2} \mathrm{O}$ & $5,16( \pm 0,36)$ & $5,00( \pm 0,17)$ & $4,79( \pm 0,31)$ & $4,81( \pm 0,26)$ & $4,67( \pm 0,22)$ \\
\hline$P$ & $\mathrm{mg} \mathrm{dm}{ }^{-3}$ & $1,13( \pm 0,10)$ & $0,98( \pm 0,05)$ & $1,13( \pm 0,13)$ & $1,03( \pm 0,13)$ & $1,03( \pm 0,05)$ \\
\hline K & $\mathrm{mg} \mathrm{dm}{ }^{-3}$ & $19,75( \pm 1,71)$ & $19,25( \pm 0,96)$ & $19,00( \pm 0,82)$ & $20,00( \pm 2,00)$ & $19,5( \pm 0,58)$ \\
\hline $\mathrm{Al}^{3+}$ & $\mathrm{cmol} \mathrm{dm}{ }^{-3}$ & $0,88( \pm 0,21)$ & $1,00( \pm 0,12)$ & $1,05( \pm 0,20)$ & $0,90( \pm 0,23)$ & $0,86( \pm 0,13)$ \\
\hline $\mathrm{H}+\mathrm{AL}^{(2)}$ & $\mathrm{cmol} \mathrm{dm}{ }^{-3}$ & $7,93( \pm 0,89)$ & $7,08( \pm 0,34)$ & $6,60( \pm 0,05)$ & $6,28( \pm 1,34)$ & $6,95( \pm 0,10)$ \\
\hline $\mathrm{T}^{(3)}$ & $\mathrm{cmol} \mathrm{dm}{ }^{-3}$ & $8,26( \pm 0,90)$ & $7,54( \pm 0,34)$ & $7,14( \pm 0,51)$ & $6,93( \pm 1,30)$ & $7,71( \pm 0,13)$ \\
\hline $\mathrm{M} 0^{(4)}$ & $\operatorname{dagkg}^{-1}$ & $3,36( \pm 0,13)$ & $3,40( \pm 0,14)$ & $3,26( \pm 0,20)$ & $3,43( \pm 0,19)$ & $3,49( \pm 0,08)$ \\
\hline $\mathrm{Cu}$ & $\mathrm{mg} \mathrm{dm}-3$ & $1,73( \pm 0,15)$ & $1,69( \pm 0,16)$ & $1,78( \pm 0,14)$ & $1,99( \pm 0,45)$ & $1,98( \pm 0,39)$ \\
\hline $\mathrm{Ni}$ & $\mathrm{mg} \mathrm{dm} \mathrm{m}^{-3}$ & $0,03( \pm 0,07)$ & $0,31( \pm 0,33)$ & $0,01( \pm 0,02)$ & $0,39( \pm 0,45)$ & $0,25( \pm 0,30)$ \\
\hline $\mathrm{Cd}$ & $\mathrm{mg} \mathrm{dm} \mathrm{m}^{-3}$ & $0,03( \pm 0,04)$ & $0,03( \pm 0,01)$ & $0,04( \pm 0,02)$ & $0,01( \pm 0,02)$ & $0,06( \pm 0,04)$ \\
\hline $\mathrm{Pb}$ & $\mathrm{mg} \mathrm{dm} \mathrm{m}^{-3}$ & $0,68( \pm 0,12)$ & $0,56( \pm 0,04)$ & $0,69( \pm 0,13)$ & $0,56( \pm 0,12)$ & $0,58( \pm 0,22)$ \\
\hline $\mathrm{Ca}^{2+}$ & $\mathrm{cmol} \mathrm{dm}-3$ & $0,21( \pm 0,02)$ & $0,33( \pm 0,03)$ & $0,4( \pm 0,05)$ & $0,50( \pm 0,05)$ & $0,59( \pm 0,04)$ \\
\hline $\mathrm{Mg}^{2+}$ & $\mathrm{cmol} \mathrm{dm}^{-3}$ & $0,07( \pm 0,01)$ & $0,08( \pm 0,01)$ & $0,10( \pm 0,01)$ & $0,11( \pm 0,01)$ & $0,13( \pm 0,01)$ \\
\hline $\mathrm{SB}^{(5)}$ & $\mathrm{cmol} \mathrm{dm}-3$ & $0,33( \pm 0,04)$ & $0,46( \pm 0,04)$ & $0,54( \pm 0,06)$ & $0,66( \pm 0,06)$ & $0,76( \pm 0,05)$ \\
\hline $\mathrm{t}^{(6)}$ & $\mathrm{cmol} \mathrm{dm}-3$ & $1,21( \pm 0,20)$ & $1,46( \pm 0,09)$ & $1,59( \pm 0,16)$ & $1,56( \pm 0,19)$ & $1,62( \pm 0,16)$ \\
\hline$V^{(7)}$ & $\%$ & $4,03( \pm 0,53)$ & $6,13( \pm 0,59)$ & $7,63( \pm 0,79)$ & $9,93( \pm 2,97)$ & $9,85( \pm 0,57)$ \\
\hline $\mathrm{m}^{(8)}$ & $\%$ & $72,03( \pm 6,04)$ & $68,38( \pm 4,12)$ & $65,43( \pm 6,67)$ & $57,10( \pm 8,62)$ & $52,78( \pm 3,43)$ \\
\hline Mn & $\mathrm{mg} \mathrm{dm}{ }^{-3}$ & $8,15( \pm 1,82)$ & $9,98( \pm 0,90)$ & $11,35( \pm 1,13)$ & $15,23( \pm 2,44)$ & $16,45( \pm 2,42)$ \\
\hline $\mathrm{Zn}$ & $\mathrm{mg} \mathrm{dm}{ }^{-3}$ & $0,52( \pm 0,07)$ & $0,95( \pm 0,30)$ & $1,16( \pm 0,07)$ & $1,35( \pm 0,26)$ & $1,5( \pm 0,20)$ \\
\hline $\mathrm{Fe}$ & $\mathrm{mg} \mathrm{dm}{ }^{-3}$ & $227,5( \pm 84,32)$ & $247,3( \pm 56,21)$ & $280,5( \pm 59,64)$ & $415,5( \pm 218,39)$ & $479,7( \pm 57,13)$ \\
\hline $\mathrm{Cr}$ & $\mathrm{mg} \mathrm{dm}{ }^{-3}$ & $0,74( \pm 0,89)$ & $1,35( \pm 0,43)$ & $1,09( \pm 0,13)$ & $2,17( \pm 1,12)$ & $2,64( \pm 0,60)$ \\
\hline
\end{tabular}

(1) Parâmetros; ${ }^{(2)}$ Acidez potencial; ${ }^{(3)}$ Capacidade de troca de cátions a pH 7; ${ }^{(4)}$ Matéria Orgânica; ${ }^{(5)}$ Soma de bases; ${ }^{(6)}$ Capacidade de troca de cátions efetiva; ${ }^{(7)}$ Saturação por bases; ${ }^{\left({ }^{(8)}\right.}$ Saturação por alumínio; ${ }^{(9)}$ média (+- desvio padrão).

Fonte: Oliveira et al. 2015. 
0 experimento foi montado seguindo um delineamento inteiramente casualizado (DIC), visto que a fonte de variação é apenas as doses do lodo de ETA. As 20 unidades experimentais foram subdivididas em cinco tratamentos (T0, T1, T2, T3 e T4) e cada um desses tratamentos com quatro repetições (R1, R2, R3 e R4).

Com intuito de avaliar o potencial agronômico do LETA foram plantadas duas mudas de capim da espécie Cynodon sp. Tifton 85 por embalagens, cada muda padronizada quanto ao comprimento e espessura.

Para uniformizar as unidades experimentais, após os primeiros 21 dias de plantio fez-se uma poda do capim a $10 \mathrm{~cm}$ de altura em relação ao nível do solo. Posteriormente a esta uniformização, o primeiro ciclo teve seu início em outubro de 2015 (31/10/2015), seguindo a recomendação de Malavolta (1992), quanto à época padronizada (primavera e/ou verão) para amostragem das folhas de gramíneas, que favorece o melhor desenvolvimento das plantas, devido condições adequadas de temperatura e luminosidade neste período (MATOS et al., 2013). Nos quarenta e cinco dias ao final do ciclo, as plantas foram cortadas novamente a $10 \mathrm{~cm}$ de altura em relação ao nível do solo. Após este corte, em dezembro de 2015 (15/12/2015), o capim passou por outro sucessivo ciclo de crescimento, com a mesma duração de 45 dias.

0 manejo da irrigação seguiu o turno de rega diário e as lâminas d’água foram determinadas utilizando-se a equação Penman Monteith adaptado de Allen et al. (1998), Equação 1.

$$
\mathrm{ET}_{\mathrm{pc}}=\mathrm{K}_{\mathrm{C}} \frac{0,408 \Delta(\mathrm{Rn}-\mathrm{G}) \gamma\left(\frac{900}{\mathrm{~T}_{+273}}\right) \mathrm{U}_{2}\left(\mathrm{e}_{\mathrm{s}}-\mathrm{e}_{\mathrm{a}}\right)}{\Delta^{+} \gamma\left(\mathrm{l}+0,34 \mathrm{U}_{2}\right)} \quad \text { Equação } 1
$$

Onde: ETPC - Evapotranspiração potencial da cultura; Kc - Coeficiente da cultura; $\mathbf{\gamma}$ Constante psicrométrica, $\mathrm{em} \mathrm{KPa}^{\circ} \mathrm{C}-1 ; \boldsymbol{\Delta}$ - Declividade da curva de pressão de vapor de saturação, em Kpa ${ }^{\circ} \mathrm{C}-1$; es- Pressão de saturação de vapor, em KPa; ea- Pressão de vapor em vapor atual, em KPa; (es-ea) - Déficit de pressão de vapor ,em KPa; $\mathrm{U}_{2}$ - Velocidade de vento à altura de $2 \mathrm{~m}$, em ${ }^{\circ} \mathrm{C}$; T - Temperatura do ar a $2 \mathrm{~m}$ de altura; $\mathbf{G}$ - Fluxo de calor no solo, em MJ m-2 ${ }^{2} \mathrm{c}-\mathrm{l}$; Rn - Saldo de radiação à superfície, em MJ m-2d-1. 
Avaliação do desenvolvimento do capim Tifton cultivado em latossolo adubado com lodo de ETA

0s parâmetros meteorológicos foram coletados diariamente da estação automática do INMET, referente a cidade de Juiz de Fora no período de interesse e foram manipulados a fim de garantir o cálculo de ETPC e a lâmina d'água requerida pela cultura a cada dia. Na Figura 1 está representada a lâmina d'água de irrigação diariamente do capim Tifton 85, calculada referente os parâmetros meteorológicos de Juiz de Fora entre os dias que sucederam o $1^{0}$ e $2^{0}$ ciclo do plantio.

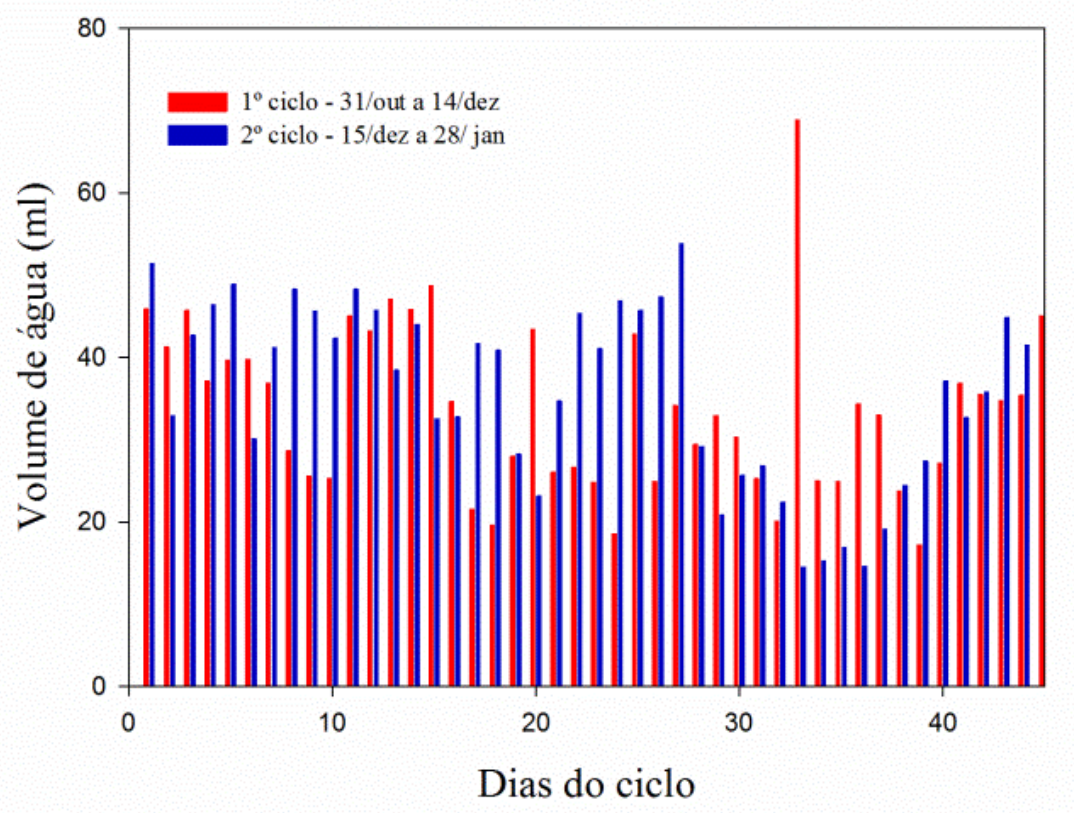

Figura 1. Lâmina d'água irrigadas diariamente do capim Tifton 85 , referente $1^{0}$ ciclo $(31 / 10 / 15$ a $15 / 12 / 15)$ e $2^{\circ}(15 / 12 / 15$ a $29 / 01 / 16)$ ciclo do plantio

Fonte: Própria.

Foram avaliadas características de comprimento, produção de massa seca e acúmulo de nutrientes para cada ciclo. Ao fim de cada ciclo foi realizado a medida do comprimento da parte aérea com auxílio de uma trena da base do colo, onde houve o corte, até gema apical que deu origem a última folha.

A análise de produção foi realizada no Laboratório de Qualidade Ambiental (LAQUA) do Departamento de Engenharia Sanitária e Ambiental, da UFJF para determinar a massa seca. A determinação da massa seca foi obtida após o vegetal ter sido colocado na estufa por 5 dias à $40^{\circ}$ C.Para o primeiro ciclo foi analisado o rendimento apenas da parte aérea da cultura. Já, para o segundo ciclo, fez-se análise tanto da parte aérea quanto da radícula. No entanto, para 
determinação da massa seca radicular as raízes foram lavadas em água corrente sobre uma peneira, colocadas em sacos de papel e posteriormente submetida a desidratação na estufa assim como para parte aérea.

0 acúmulo de metais foi estudado através de análises do solo e vegetal. Estas análises se complementam para proporcionar informações que permitam a adubação adequada para 0 melhor desenvolvimento do Capim Tifton 85 (MALAVOLTA, 1992). A análise vegetal retrata 0 estado nutricional da cultura e este conhecimento da deficiência ou excesso dos nutrientes limitantes ao desenvolvimento vegetal é essencial para maximizar o seu potencial produtivo (SARMENT0 et al., 2006).

Posterior à secagem, as amostras do material vegetal foram conduzidas para 0 Laboratório de Análise de Solo, Tecido vegetal e fertilizante da Universidade Federal de Viçosa (UFV), para a determinação dos teores de Cobre, Ferro, Zinco e Manganês, conforme a método apresentada pela EMBRAPA (1999). Designou-se a análise de tais metais, baseada nos valores encontrados por Oliveira et al. (2015), uma vez que estes apresentaram teores discrepantes no solo adubado com LETA e por se tratarem de elementos com potencial de toxicidade.

Assim como para a análise de produção, no primeiro ciclo a quantificação dos teores dos metais foi realizada apenas da parte aérea da planta, enquanto que no segundo ciclo foi avaliado tanto na raiz quanto na porção aérea.

Os dados obtidos foram submetidos à análise de variância (ANOVA), as médias dos resultados foram comparadas pelo método de Tukey considerando o nível de significância de 5\%. Para a análises foram usados o programa de análises estatísticas e planejamento de experimentos, SISVAR versão 5.3 (FERREIRA, 2011), e o software SIGMAPLOT para ajuste de modelos.

\section{RESULTADOS E DISCUSSÃ0}

Na Tabela 4 estão apresentados os resultados do crescimento, produção de massa seca e produtividade da parte aérea do capim Tifton 85.

Verificou-se que as médias da massa seca, da produtividade e comprimento do capim Tifton 85 não diferiram significativamente entre si pelo teste de Tukey, com 5\% de significância, 
Avaliação do desenvolvimento do capim Tifton cultivado em latossolo adubado com lodo de ETA

com exceção da massa seca e a produtividade do segundo ciclo. Pelo método de ajuste de curva, representado na Figura 2, considerando que a curva mantenha o mesmo comportamento, pode se considerar que a massa seca do capim Tifton 85 tende a aumentar com o aumento de taxa de aplicação de LETA ao solo. A curva de ajuste de modelo da produção de massa seca seguiu o mesmo comportamento da curva de massa seca, o que é coerente uma vez que, uma variável é dependente da outra.

Tabela 4 - Crescimento, produção de massa seca e produtividade da parte aérea do capim Tifton 85 cultivado em um Latossolo adubado com LETA, referente ao primeiro e o segundo ciclo de cultivo

\begin{tabular}{|c|c|c|c|c|c|c|}
\hline & \multicolumn{6}{|c|}{ Sistema Aéreo } \\
\hline \multirow[b]{2}{*}{ Trat.(1) } & \multicolumn{3}{|c|}{$1^{0}$ Ciclo } & \multicolumn{3}{|c|}{$2^{\circ}$ Ciclo } \\
\hline & $\begin{array}{c}\text { Comp. }{ }^{(2)} \\
(\mathrm{cm}) \\
\end{array}$ & $\begin{array}{c}\text { Massa seca } \\
\text { (g) }\end{array}$ & $\begin{array}{l}\text { Produtiv. }{ }^{(3)} \\
\left(\mathrm{Mg} \mathrm{ha}^{-1}\right)\end{array}$ & $\begin{array}{c}\text { Comp. }{ }^{(2)} \\
\text { (cm) }\end{array}$ & $\begin{array}{c}\text { Massa seca } \\
\text { (g) }\end{array}$ & $\begin{array}{l}\text { Produtiv. }{ }^{(3)} \\
\left(\mathrm{Mg} \mathrm{ha}^{-1}\right)\end{array}$ \\
\hline T0 & $29,02( \pm 11,30) \mathrm{a}$ & $0,70( \pm 0,67) \mathrm{a}$ & $0,34( \pm 0,33) \mathrm{a}$ & $24,54( \pm 4,40) \mathrm{a}$ & $0,83( \pm 0,34) \mathrm{ab}$ & $0,41(0,17) \mathrm{ab}$ \\
\hline $\mathrm{Tl}$ & $30,02( \pm 4,15) \mathrm{a}$ & $0,65( \pm 0,64) \mathrm{a}$ & $0,32( \pm 0,24) \mathrm{a}$ & $28,87( \pm 3,04) \mathrm{a}$ & $0,59( \pm 0,08) \mathrm{a}$ & $0,29( \pm 0,03) \mathrm{a}$ \\
\hline $\mathrm{T} 2$ & $25,06( \pm 2,58) \mathrm{a}$ & $1,27( \pm 0,40) \mathrm{a}$ & $0,62( \pm 014) \mathrm{a}$ & $28,08( \pm 5,75) \mathrm{a}$ & $1,38( \pm 0,42) \mathrm{BC}$ & $0,68( \pm 0,18) \mathrm{bc}$ \\
\hline T3 & $33,7( \pm 7,54) \mathrm{a}$ & $0,90( \pm 0,24) \mathrm{a}$ & $0,44(0,12) \mathrm{a}$ & $36,00( \pm 7,81) \mathrm{a}$ & $0,94( \pm 0,18) \mathrm{abc}$ & $0,46( \pm 0,09) \mathrm{abc}$ \\
\hline $\mathrm{T} 4$ & $34,95( \pm 3,15) \mathrm{a}$ & $1,50( \pm 0,06) \mathrm{a}$ & $0,74( \pm 0,03) \mathrm{a}$ & $33,61( \pm 1,88) \mathrm{a}$ & $1,44( \pm 0,18)_{\mathrm{C}}$ & $0,71( \pm 0,09)_{\mathrm{C}}$ \\
\hline
\end{tabular}

Médias seguidas pela mesma letra, não difere entre si pelo teste de Tukey, a $5 \%$ de probabilidade.

(1)Tratamento; (2)Comprimento; (3)Produtividade.

Fonte: Autoria própria.
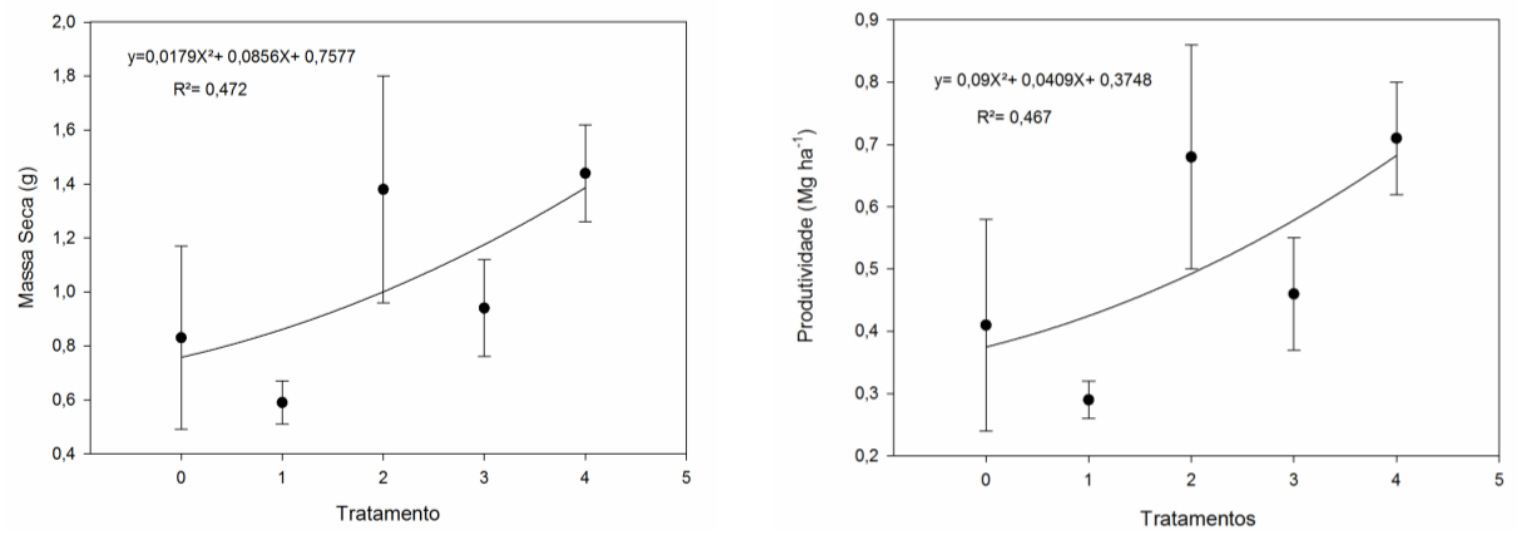

Figura 2. Curva de ajuste de modelo da variação de massa seca e produtividade do $2^{\circ}$ ciclo em função aos distintos tratamentos.

Fonte: Própria. 
De acordo com os dados apresentados na Tabela 4, a produtividade de massa seca (MS) foi maior no segundo corte para a maioria dos tratamentos, tal como também observado no trabalho de Fia et al. (2011) que estudaram o comportamento do capim Tifton 85 no tratamento das águas residuárias da suinocultura.

Na Tabela 4 pode-se analisar ainda que os valores de produtividade de MS obtidos foram inferiores aos reportados por Matos et al. (2013) que teve a maior produtividade acumulada de MS próximo a 2,6 Mg ha ${ }^{-1}$ ao adubar o solo com uma taxa de $0,75 \mathrm{Mg} \mathrm{ha}^{-1} \mathrm{~d}^{-1} \mathrm{de}$ DB0 de percolado de resíduo sólido urbano. Da mesma forma, a produtividade encontrada neste trabalho, foi inferior ao relatado por Fia et al. (2011), que obtiveram produtividades de 4,73 a 6,26 $\mathrm{Mg} \mathrm{ha}^{-1}$, no primeiro e segundo cortes, respectivamente, aplicando carga de 0, $32 \mathrm{Mg} \mathrm{ha}^{-1} \mathrm{~d}^{-1} \mathrm{de}$ DB0 de água residuária de suinocultura. Assim, Fia et al. (2011) encontraram aproximadamente 12\% à mais de produtividade, se comparado com tratamento de maior produtividade deste trabalho, T4 do $1^{0}$ ciclo $\left(0,74 \mathrm{Mg} \mathrm{ha}^{-1}\right)$. A baixa produtividade do Capim Tifton 85, neste trabalho, pode ser em resposta ao baixo potencial do LETA de trazer melhoria a um solo agronomicamente pobre, demonstrado pelo índice saturação de base (V) inferior a 50\%, a acidez potencial (H+AL) alta e capacidade de troca de cátions efetiva (t) baixa, conforme apresentado na Tabela 3.

Tabela 5 - Teores de cobre $(\mathrm{Cu})$ da parte aérea e radicular do capim Tifton 85 cultivado em um Latossolo adubado com LETA, referente ao primeiro e segundo ciclo de cultivo

\begin{tabular}{c|c|c|c}
\hline \multirow{2}{*}{ Tratamento } & \multicolumn{2}{|c}{ Sistema Aéreo } & Sistema radicular \\
\cline { 2 - 4 } & $\mathbf{1}^{\mathbf{0}}$ Ciclo & $\mathbf{2}^{\mathbf{0}}$ Ciclo & $\mathbf{2}^{\mathbf{0}}$ Ciclo \\
\cline { 2 - 4 } & \multicolumn{3}{|c}{ Cobre (Cu) } \\
\cline { 2 - 4 } & \multicolumn{3}{|c}{$\left(\mathbf{m g ~ K g}^{-1}\right)$} \\
T0 & $9,124( \pm 2,59) \mathrm{a}$ & $10,463( \pm 2,21) \mathrm{a}$ & $40,138( \pm 18,59) \mathrm{a}$ \\
T1 & $9,070( \pm 1,27) \mathrm{a}$ & $12,463( \pm 2,11) \mathrm{a}$ & $30,525( \pm 7,78) \mathrm{a}$ \\
T2 & $8,188( \pm 1,49) \mathrm{a}$ & $11,563( \pm 2,06) \mathrm{a}$ & $33,500( \pm 10,08) \mathrm{a}$ \\
T3 & $7,700( \pm 0,83) \mathrm{a}$ & $9,388( \pm 1,03) \mathrm{a}$ & $26,713( \pm 17,18) \mathrm{a}$ \\
T4 & $9,955( \pm 2,67) \mathrm{a}$ & $10,888( \pm 1,96) \mathrm{a}$ & $34,863( \pm 5,27) \mathrm{a}$ \\
\hline
\end{tabular}

Fonte: Autoria própria.

Diante do resultado apresentado pela Tabela 5 , as médias do teor de cobre não variaram significativamente entre os tratamentos, pelo Teste de Tukey a 5\% de significância. 
Avaliação do desenvolvimento do capim Tifton cultivado em latossolo adubado com lodo de ETA

0 cobre desempenha funções nas plantas como de ativação de enzimas, síntese de proteína, metabolismo de carboidratos e fixação simbiótica de $\mathrm{N}_{2}$ (MALAVOLTA, 1980).

Nota-se que não houve um significativo aumento do teor de cobre entre o tratamento (T0) sem adubação de LETA e os com adubação (T1, T2, T3 e T4). Observa-se também que houve uma maior absorção pelo capim Tifton 85 de cobre pelas raízes em relação à parte aérea. Resultado semelhante foi relatado por Malavolta et al. (1997), o cobre tende a acumular-se nas raízes onde, em casos de toxidade, é o primeiro órgão que manifesta os sintomas de mau funcionamento, de escurecimento e perda de elementos previamente absorvidos.

A concentração ótima de cobre na maioria das plantas, geralmente, está entre 5-20 mg $\mathrm{kg}^{-1}$ na matéria seca foliar (DECHEN e NACHTIGALL, 2006). Deficiências são prováveis quando seu teor na matéria seca foliar encontra-se em níveis inferiores a $4 \mathrm{mg} \mathrm{kg}^{-1}$ enquanto que acima de $20 \mathrm{mg} \mathrm{kg}^{-1}$ pode-se observar sintomas de toxicidade (FAQUIN, 2005). Em comparação com os valores de referência dos teores de micronutrientes nas folhas dos autores citado acima e Malavolta (1992), na Tabela 6, observou-se que o cobre encontrado esta dentro da faixa adequada para o crescimento normal das plantas.

Tabela 6 - Concentração e classificação de micronutrientes nas folhas de gramíneas

\begin{tabular}{c|c|cccc}
\hline \multirow{2}{*}{ Cultura } & \multirow{2}{*}{ Classificação } & Cobre (Cu) & Ferro (Fe) & $\begin{array}{c}\text { Manganês } \\
(\mathbf{M n})\end{array}$ & $\begin{array}{c}\text { Zinco } \\
\text { (Zn) }\end{array}$ \\
\cline { 3 - 6 } & & \multicolumn{4}{|c}{$\left.\mathbf{( m g ~ k g}^{-1}\right)$} \\
\hline \multirow{2}{*}{$\begin{array}{c}\text { Gramíneas } \\
\text { (geral) }\end{array}$} & Baixa & $<2$ & $<80$ & $<60$ & $<10$ \\
& Média & $2-4$ & $80-99$ & $60-79$ & $10-19$ \\
& Adequado & $5-15$ & $100-200$ & $80-300$ & $20-50$ \\
\hline
\end{tabular}

Fonte: Adaptado de Malavolta, 2012.

Para Dechen e Nachtigall (2006), entre todos os micronutrientes, a deficiência de cobre é a mais difícil de diagnosticar devido à interferência de outros elementos (P, Fe, Mo, Zn e S), além da deficiência de cobre apresentar-se raramente nas plantas, uma vez que este elemento se encontra disponível em quase todos os solos.

Observa-se ainda na Tabela 5, que o aumento das taxas de aplicação de LETA, entre os tratamentos, não foram suficientes para que houvesse uma tendência de aumento dos teores 
de cobre no capim Tifton 85 assim como, relatado por Fia et al. (2011) que estudaram o comportamento do capim Tifton 85 no tratamento das águas residuárias da suinocultura.

Observa-se na Tabela 7 que não ocorreu diferença do valor de zinco na planta entre os cincos tratamentos pelo Teste de Tukey ao nível de significância de 5\%.

Tabela 7 - Teores de zinco (Zn) da parte aérea radicular do capim Tifiton 85 cultivado em um Latossolo adubado com LETA, referente ao primeiro e/ou segundo ciclo de cultivo

\begin{tabular}{c|c|c|c}
\hline \multirow{2}{*}{ Tratamento } & \multicolumn{2}{|c}{ Sistema Aéreo } & Sistema radicular \\
\cline { 2 - 4 } & $\mathbf{1}^{\mathbf{0}}$ Ciclo & $\mathbf{2}^{\mathbf{0}}$ Ciclo & $\mathbf{2}^{\mathbf{0}}$ Ciclo \\
\cline { 2 - 4 } & \multicolumn{3}{|c}{ Zinco (Zn) $^{\left(\mathbf{m g ~ K g}^{-1}\right)}$} \\
\cline { 2 - 4 } & $40,404( \pm 14,70) \mathrm{a}$ & $29,675( \pm 592) \mathrm{a}$ & $34,513( \pm 8,05) \mathrm{a}$ \\
T0 & $39,201( \pm 2,44) \mathrm{a}$ & $43,763( \pm 8,92) \mathrm{a}$ & $40,350( \pm 12,90) \mathrm{a}$ \\
T1 & $41,113( \pm 2,39) \mathrm{a}$ & $32,488( \pm 5,81) \mathrm{a}$ & $41,163( \pm 1,59) \mathrm{a}$ \\
T3 & $43,300( \pm 6,62) \mathrm{a}$ & $37,125( \pm 2,40) \mathrm{a}$ & $31,275( \pm 3,15) \mathrm{a}$ \\
T4 & $59,275( \pm 18,54) \mathrm{a}$ & $39,600( \pm 4,50) \mathrm{a}$ & $37,225( \pm 16,29) \mathrm{a}$ \\
\hline
\end{tabular}

Médias seguidas pela mesma letra, não difere entre si pelo teste de Tukey, a $5 \%$ de probabilidade. Fonte: Autoria própria.

As concentrações de Zn nas plantas variam entre 3 e $150 \mathrm{mg} \mathrm{kg}^{-1}$ de massa seca da planta (DECHEN e NACHTIGALL, 2006). Considera-se que concentrações entre 20 a $50 \mathrm{mg} \mathrm{kg}^{-1}$ (Tabela 6) são os valores adequados ao crescimento normal de gramíneas (MALAVOLTA, 1992).

Segundo Malavolta (1980) a presença de cobre e ferro pode inibir a absorção de Zn, mesmo a mistura solo-lodo tendo apresentado a presença desses metais, o capim Tifton 85 apresentou teores de Zn no limite de adequação. De acordo com o resultado acima, isso pode ser justificado pelo fato de que gramíneas forrageiras têm alta eficiência na absorção de zinco (MALAVOLTA, 1980).

Diante do resultado exposto na Tabela 8, verificou-se que não ocorreu diferença dos teores de ferro na planta entre os cinco tratamentos, pelo Teste de Tukey ao nível de significância de $5 \%$. 
Avaliação do desenvolvimento do capim Tifton cultivado em latossolo adubado com lodo de ETA

Tabela 8 - Teores de ferro $(\mathrm{Fe})$ da parte aérea e radicular do capim Tifiton 85 cultivado em um Latossolo adubado com LETA, referente ao primeiro e segundo ciclo de cultivo

\begin{tabular}{c|c|c|c}
\hline \multirow{2}{*}{ Trat. } & \multicolumn{2}{|c}{ Sistema Aéreo } & \multicolumn{1}{c}{ Sistema radicular } \\
\cline { 2 - 4 } & $\mathbf{1}^{\mathbf{0}}$ Ciclo & $\mathbf{2}^{\mathbf{0} \text { Ciclo }}$ & $\mathbf{2}^{\mathbf{0}}$ Ciclo \\
\cline { 2 - 4 } & \multicolumn{3}{|c}{ Ferro (Fe) } \\
\cline { 2 - 4 } & \multicolumn{3}{|c}{$\left(\mathbf{m g ~ K g}^{-1}\right)$} \\
T0 & $161,346( \pm 8,95) \mathrm{a}$ & $314,513( \pm 59,25) \mathrm{a}$ & $24589,750( \pm 8279,51) \mathrm{a}$ \\
T1 & $194,150( \pm 49,78) \mathrm{a}$ & $507,138( \pm 404,81) \mathrm{a}$ & $23585,750( \pm 6115,25) \mathrm{a}$ \\
T2 & $226,788( \pm 52,76) \mathrm{a}$ & $351,213( \pm( \pm 316,64) \mathrm{a}$ & $18678,197( \pm 10257,80) \mathrm{a}$ \\
T3 & $178,063( \pm 37,18) \mathrm{a}$ & $239,088( \pm 129,76) \mathrm{a}$ & $19032,250( \pm 3276,18) \mathrm{a}$ \\
T4 & $260,819( \pm 257,51) \mathrm{a}$ & $208,838( \pm 68,60) \mathrm{a}$ & $25509,750( \pm 8383,53) \mathrm{a}$ \\
\hline
\end{tabular}

Médias seguidas pela mesma letra, não difere entre si pelo teste de Tukey, a 5\% de probabilidade.

(1) Tratamento

Fonte: Autoria própria.

0 ferro é componente de uma série de enzimas que desempenha funções nas plantas como síntese de proteínas, síntese de clorofila entre outras (FAQUIN, 2005).

Segundo aos teores recomendados por Malavolta (1992) (Tabela 6) e baseado nos dados da Tabela 8 verifica-se que para o capim Tifton 85 o tratamento T2, T4 do primeiro ciclo e todos os tratamentos do segundo ciclo excederam o limite máximo de $200 \mathrm{mg} \mathrm{kg}^{-1}$ adequado para 0 crescimento normal das gramíneas. 0 sistema radicular também apresentou valores maiores que este limite. Para Dechen e Nachtigall (2006) as concentrações de ferro nas plantas variam, dependendo da parte da planta e da espécie.

Em geral, os teores de ferro encontrado neste trabalho estão relativamente abaixo dos teores de ferro encontrado por Matos et al. (2013), no $1^{0}$ corte do capim adubado com percolado de resíduo sólido, onde o teor de ferro chegou a $1419 \mathrm{mg} \mathrm{Kg}^{-1}$, que referenciava a tratamentos em que foram aplicadas taxas mais altas de percolado de resíduos urbano $\left(1.000 \mathrm{~kg} \mathrm{ha}^{-1} \mathrm{~d}^{-1} \mathrm{de}\right.$ DB0).

0 alto teor de ferro observado no capim Tifton 85 é proveniente da alta concentração de ferro já presente no solo e a incorporação do LETA, que contribuiu para elevar ainda mais a concentração deste elemento. 0 que pode ser atestado pelo fato do tratamento T0 (sem incorporação de lodo) já apresentar valores elevados de ferro, conforme apresentado na Tabela 3. Segundo Malavolta (1980) o ferro é o micronutriente que se apresenta em maior teor no solo brasileiro. 
A possível toxidade por ferro pode ser notada, através do aparecimento manchas necróticas e o amarelamento-pardo das folhas da maioria dos tratamentos, que são sintomas de toxidade por ferro que foram notados visivelmente neste trabalho.

De acordo com o resultado da média de Manganês, nota-se que não ocorreu diferença do valor de manganês no sistema aéreo entre os cincos tratamentos, pelo Teste de Tukey ao nível de significância de 5\%. Mas, no sistema radicular, o T4 apresentou uma diferença significativa entre os tratamentos T0, T1 e T2 segundo teste de Tukey\%.

Tabela 9 - Teores de manganês $(\mathrm{Mn})$ da parte aérea e radicular do capim Tifiton 85 cultivado em um Latossolo adubado com LETA, referente ao primeiro e segundo ciclo de cultivo

\begin{tabular}{c|c|c|c}
\hline \multirow{2}{*}{ Tratamento } & \multicolumn{2}{|c|}{ Sistema Aéreo } & Sistema radicular \\
\cline { 2 - 4 } & $\mathbf{1}^{\mathbf{0}}$ Ciclo & $\mathbf{2}^{\mathbf{0}}$ Ciclo & $\mathbf{2}^{\mathbf{0}}$ Ciclo \\
\cline { 2 - 4 } & \multicolumn{3}{|c}{ Manganês $\mathbf{( M n})$} \\
\cline { 2 - 4 } & $436,698( \pm 73,56) \mathrm{a}$ & $268,025( \pm 62,87) \mathrm{a}$ & $133,738( \pm 14,12) \mathrm{a}$ \\
T0 & $396,024( \pm 125,89) \mathrm{a}$ & $349,125( \pm 71,40) \mathrm{a}$ & $153,938( \pm 20,21) \mathrm{a}$ \\
T1 & $549,325( \pm 110,07) \mathrm{a}$ & $338,763( \pm 72,86) \mathrm{a}$ & $158,500( \pm 27,85) \mathrm{a}$ \\
T2 & $524,375( \pm 71,06) \mathrm{a}$ & $345,550( \pm 52,47) \mathrm{a}$ & $175,113(14,28) \mathrm{ab}$ \\
T3 & $494,549( \pm 141,50) \mathrm{a}$ & $277,638( \pm 53,37) \mathrm{a}$ & $274,500( \pm 98,06) \mathrm{b}$ \\
\hline
\end{tabular}

Médias seguidas pela mesma letra, não difere entre si pelo teste de Tukey, a $5 \%$ de probabilidade. Fonte: Autoria própria.

Nota-se na Figura 3, a apresentação da curva que melhor se ajustou o modelo. Observase que houve uma tendência de aumento de teores de manganês nas raízes do capim Tifton 85 com o aumento de incorporação do LETA. 


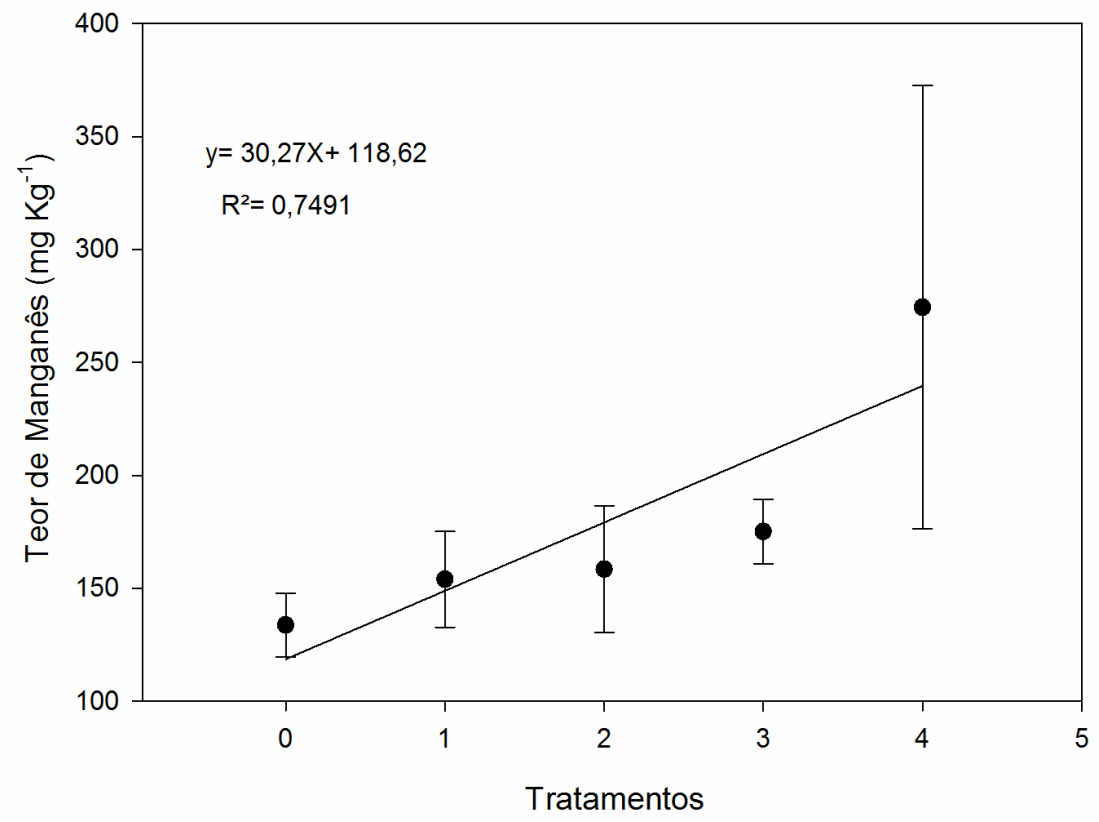

Figura 3. Curva de ajuste de modelo da variação de teor de manganês no sistema radicular do capim Tifton 85 em função aos distintos tratamentos Fonte: Própria.

Na Tabela 9, verificou-se uma tendência de diminuição do teor de manganês da parte aérea do capim Tifton 85, com o aumento do número de cortes da planta, pois os maiores valores foram encontrados no $1^{0}$ ciclo, este comportamento também foi relatado por Matos et al. (2013).

Conforme Faquin (2005) a acidez do solo, predominante na região subtropical e tropical, favorece a disponibilidade de manganês, tornando mais ocorrente à toxidade do que a deficiência deste micronutriente nas plantas. 0 solo usado neste trabalho apresentava pH ácido ,entre 4 e 5,e valores elevados de manganês, Tabela 3. Observa-se também, na Tabela 1, que o manganês é o elemento de maior teor no LETA.

Para Dechene Nachtigall (2006) as concentrações de manganês nas plantas variam entre 5 e $1500 \mathrm{mg} \mathrm{kg}^{-1}$ de massa seca da planta, dependendo da parte da planta e da espécie. Já para Malavolta (1992), para cultura de gramíneas essa faixa é mais restrita, 80-300 mg $\mathrm{kg}^{-1}$ representa valores para uma produção adequada. De acordo com os resultados, da Tabela 9, pode se verificar conforme Malavolta (1992) na Tabela 6, que os teores de manganês presente no capim Tifton 85 excederam o limite adequado para um crescimento normal de gramíneas. 
A concentração de manganês nas folhas do Tifton 85, obtidas em todos os tratamentos neste trabalho, superou as concentrações encontradas por Matos et al. (2013) que teve o valor máximo de manganês igual a $276 \mathrm{mg} \mathrm{kg}$,encontrado no $1^{0}$ ciclo do tratamento que recebeu maior taxa de percolado de resíduo urbano $\left(1 \mathrm{Mg}_{\mathrm{ha}}{ }^{-1} \mathrm{~d}^{-1} \mathrm{de} \mathrm{DB} 0\right)$.

Dada a interação do manganês com outros nutrientes, o seu excesso pode manifestar-se como deficiência induzida de cálcio, magnésio e, em especial, de ferro e, só posteriormente, como toxidez, o que pode ter inibido uma parcela de absorção de ferro pelo capim Tifton e diminuindo os efeitos da toxidade de ferro na planta (FAQUIN, 2005).

Segundo Faquin (2005) a toxidade de manganês pode ocasionar até 10\% de redução da produção de matéria seca da planta, o que pode ter influenciado também na baixa produtividade de matéria seca do capim Tifton 85.0 mesmo autor relata que a toxidade por manganês é manifestada em muitas culturas e pode ser compensada por meio de calagem.

A função desempenhada pelo Mn é na síntese de proteína e multiplicação de células e síntese de clorofila (MALAVOLTA, 1980).

Embora ainda sejam inexistentes legislações específicas para a disposição do LETA em solo, muitos autores se baseiam na resolução CONAMA 375/06, que define concentrações máximas de substâncias inorgânicas e patógenos do resíduo gerado nas estações de tratamento de esgoto (ETE) para a disposição em solos destinados à agricultura (CONAMA, 2006). Segundo Ramalho (2015) a análise dos riscos ambiental e sanitário, existentes na aplicação do LETA na agricultura deve estar em acordo com o estabelecido pelo CONAMA 375/06. Na Tabela 10, está apresentados teores de substâncias inorgânicas adicionadas ao solo em função de cada dosagem do tratamento e limite máximo permitido pela CONAMA 375/06 para disposição de lodo de ETA no solo. 
Avaliação do desenvolvimento do capim Tifton cultivado em latossolo adubado com lodo de ETA

Tabela 10 - Teores de substâncias inorgânicas adicionadas ao solo em função do tratamento e limite máximo permitido pela CONAMA 375/06 para disposição no solo

\begin{tabular}{c|c|c|c|c|c|c}
\cline { 2 - 7 } & T0 & T1 & T2 & T3 & T4 & $\begin{array}{c}\text { Concentração máx. } \\
\text { permitida pela } \\
\text { C0NAMA 375/06 }\end{array}$ \\
\hline Parâmetro & \multicolumn{7}{|c}{ mg Kg-1 $^{-1}$} \\
\hline Cádmo & 0,0 & 103,6 & 207,2 & 310,8 & 592,2 & 39 \\
Chumbo & 0,0 & 59,2 & 118,4 & 177,6 & 338,4 & 300 \\
Cobre & 0,0 & 346,9 & 693,7 & 1040,6 & 1982,7 & 1500 \\
Crômio & 0,0 & 976,0 & 1951,6 & 2927,5 & 5578,1 & 1000 \\
Níquel & 0,0 & 661,4 & 1322,6 & 1984,1 & 3780,4 & 420 \\
Zinco & 0,0 & 1436,6 & 2872,8 & 4309,5 & 8211,2 & 2800 \\
\hline
\end{tabular}

(1) Adaptado de CONAMA, 2006.

Fonte: Autoria própria.

Nota-se, pela Tabela 10, que a partir do tratamento T1, foi incorporado ao solo teores de cádmio e níquel acima do preconizado pela CONAMA 375/06.

Observa-se também, que teores de cobre e o chumbo disposto no solo no tratamento T4 foram superiores ao determinado pela mesma. No entanto, a absorção de cobre pela cultura não variou significativamente entre o T0, sem incorporação de LETA, e T4, valores que excederam a CONAMA.

Similarmente, pode ser verificado que nos tratamentos (T2, T3 e T4) que adicionaram teores de zinco acima do limite da regulamentação não foram detectados toxidade por zinco na cultura de gramíneas.

Diante dos resultados apresentados observa-se que o lodo avaliado não apresentou potencial agronômico e as dosagens aplicadas suplantaram os limites das substancias inorgânicas preconizado pela CONAMA 375/2006. No entanto, ressalta-se que autores têm empregado este resíduo como corretivo do solo (MACHADO et al., 2005; PADILHA, 2007; RAMALH0, 2015).

Portanto, evidencia-se a necessidade de avaliação criteriosa da disponibilidade de metais pesados em LETA e de dosagem de aplicação, quando destinado à agricultura, a fim de controlar os possíveis riscos ambientas. Segundo Ramalho (2015), o LETA possui baixo risco de contaminação no que diz respeito ao aspecto sanitário. 


\section{CONCLUSÃ0}

Diante dos resultados obtidos, conclui-se que o lodo da estação de tratamento de água utilizado neste trabalho não apresenta potencial agronômico. 0 capim Tifton 85 cultivado em Latossolo Vermelho-Amarelo adubado com lodo de ETA apresentou uma tendência de aumento de produtividade e massa seca, entretanto a adubação não supriu as exigências para um adequado desenvolvimento do capim, ocasionando uma baixa produtividade e sintomas de toxidade por ferro e de excesso de manganês.

Recomenda-se para estudos futuros que concomitante a adubação com lodo de ETA realize calagem e adubação complementar para corrigir o manganês e favorecer a produtividade do Capim Tifton 85.

\section{REFERÊNCIAS BIBLIOGRÁFICAS}

ASSIS, L. R. Avaliação do impacto gerado nos corpos d'água devido ao lançamento de lodos provenientes de uma Estação de Tratamento de Água de Juiz de Fora - MG. Trabalho de conclusão de curso (Tratamento de Águas). Universidade Federal de Juiz de Fora, 2014. 61p.

ALLEN, R. G et al. Crop evapotranspiration: guidelines for computing crop water requirements. Rome: FA0, 1998. 300 p. (FA0. Irrigation and Drainage Paper, 56).

BOTERO, W. G.; SANTOS, A.; OLIVEIRA, L. C.; ROCHA, J. C. Caracterização de lodo gerado em estações de tratamento de água: perspectivas de aplicação agrícola. Quim. Nova, v. 32, n. 8 , p. 2018-2022, 2009 . Disponível em<http://www.scielo.br/pdf/qn/v32n8/v32n8a07.pdf>Acessado em: 12 jun. 2015

CONSElHO NACIONAL DO MEIO AMBIENTE- CONAMA. Ministério do Meio Ambiente (2006). Resolução no 375 , de 29 de agosto de 2006. Define critérios e procedimentos, para o uso agrícola de lodos de esgoto gerados em estações de tratamento de esgoto sanitário e seus produtos derivados, e dá outras providências.

COMPANHIA DE SANEAMENTO MUNICIPAL- CESAMA. Disponível em: <http://www.cesama.com.br/> Acesso em 14 de fev. 2016.

DECHEN, A. R.; NACHTIGALL, G. R. Micronutrientes. In: FERNANDES, M. S. (Ed.). Nutrição mineral de plantas. Viçosa: Sociedade Brasileira de Ciência do Solo, 2006. 327-354p.

DI BERNARD0, L.; SABOGAL PAZ, L.P. Seleção de Tecnologia de Tratamento de Água. Editora LDiBe LTDA.2008.878p.

EMPRESA BRASILEIRA DE PESQUISA AGROPECUÁRIA - EMBRAPA. Manual de métodos de análise de solo. $2^{\circ}$ edição Revista. Rio de Janeiro, 2011. 225p.

EMPRESA BRASILEIRA DE PESQUISA AGROPECUÁRIA. Embrapa Informática Agropecuária. Manual de análises químicas de solos, plantas e fertilizantes. Brasília: Embrapa Comunicação para Transferência de Tecnologia, 1999. 370p.

FANQUIN, V. Nutrição Mineral de Plantas, Lavras, v. Lavras: UFLA / FAEPE, 2005.186p.

FERREIRA, D. F. Sisvar: a computer statistical analysis system. Ciência e Agrotecnologia, Lavras, v. 35, p. 1039-1042, 2011.

FIA, F. R. L; MATOS, A. T.; FIA, R.; LAMBERT, T. F.; MATOS, M. P. , Remoção de nutrientes por Typhalatifoliae Cynodon spp. Cultivadas em sistemas alagados construídos. Revista Ambiente \& Água - Na Interdisciplinary Journal of Applied Science: v. 6, n. $1,2011$. 
Avaliação do desenvolvimento do capim Tifton cultivado em latossolo adubado com lodo de ETA

GUIMARÃES, M. S. Desempenho produtivo, análise de crescimento e características estruturais do dossel de dois capins do gênero Cynodon sob duas estratégias de pastejo intermitentes. Trabalho de Dissertação de Mestrado. Universidade de São Paulo, 2012, 83 p.

INSTITUT0 BRASILEIR0 DE GE0GRAFIA E ESTATÍSTICA- IBGE. Censos Demográficos de 2008. Rio de Janeiro: Fundação Instituto Brasileiro de Geografia e Estatística; 2010. Disponível em< http://censo2010.ibge.gov.br/apps/atlas/> Acessado em 19 abr. 2015.

INSTITUTO BRASILEIR0 DE GE0GRAFIA E ESTATÍSTICA- IBGE. Censos Demográficos de 2000. Rio de Janeiro: Fundação Instituto Brasileiro de Geografia e Estatística; 2015. Disponível em< http://cidades.ibge.gov.br/xtras/perfil.php?lang=\&codmun=313670\&search=minas-gerais|juiz-de-fora $>$ Acessado em 17 jan.2016

INSTITUTO NACIONAL DE METEOROLOGIA- INMET. Normais Climatológicas. Brasília - DF, 1992.

LIBÂNIO, M. Fundamentos de qualidade e tratamento de água. Editor Átomo, $2^{\circ}$ edição. Campinas 2008. 444p.

MACHADO L. C. G. T; PONTE M. X; LOPES L. N. A; PEREIRA J. A. R; Utilização de resíduo de ETA como insumo agrícola, In: CONGRESSO DA ASSOCIAÇÃO BRASILEIRA DE ENGENHARIA SANITÁRIA E AMBIENTAL, 23. Campo Grande - MS, 2005.

MALAVOLTA, E. ABC da análise de solo e folhas: amostragem, interpretação e sugestão de adubação. São Paulo: Editora Agrônomica CERES Ltda. 1992.124p.

MALAVOLTA, E. et al. Avaliação do estado nutricional das plantas: princípios e aplicações . 2 ed. Piracicaba: POTAFOS, 1997, $319 \mathrm{p.}$

MALAVOLTA, E. Elementos de nutrição mineral de plantas. Editora Agrônomica CEREs, 1980. 25lp.

MAPA DE SOLOS DO ESTADO DE MINAS GERAIS: legenda expandida. Universidade Federal de Viçosa; Fundação Centro Tecnológico de Minas Gerais; Universidade Federal de Lavras; Fundação Estadual do Meio Ambiente. Belo Horizonte: Fundação Estadual do Meio Ambiente, 2010.49

MatOS, A. T; SILVA, D. F; MONACO, P. A. V; PEREIRA, 0. G. Produtividade e composição química do capim-tifton 85 submetido a diferentes taxas de aplicação do percolado de resíduo sólido urbano. Engenharia Agrícola, Jaboticabal, v.33, n.l, p.188-200, jan./fev. 2013

OLIVEIRA, A. P. S; SILVA, J. B. G. S; PEREIRA, R. 0; SANTOS, A. S. P. Avaliação dos atributos de um latossolo adubado com lodo de estação de tratamento de água. Revista Internacional de Ciências. V .5, n.2, jul./dez. 2015, 19p.

PADILHA, C.J. Aplicação de lodos de tratamentos de água e esgoto em latossolos cultivados com milho e soja. - Dissertação de Mestrado - Universidade Federal do Paraná. - Curitiba - PR, 2007

PROGRAMA DE PESQUISAS EM SANEAMENTO BÁSICO - PROSAB. Noções gerais de tratamento e disposição final de lodos de estações de tratamento de água. Rio de Janeiro - RJ, 1999.

RAMALHO, R. P. R.S. Avaliação do uso de resíduo de estação de tratamento de água na produção de espécies vegetais com ocorrência no cerrado. Trabalho de Dissertação de Mestrado. Universidade Federal de Goiás,2015, 96 p

RICHTER, C. A. Tratamento de lodos de estações de tratamento de água. São Paulo: Editora Edgard Blucher Ltda, 2001,102 p.

SARMENT0, P.; NASCIMENT0, R. C.; MARTINS, A. T.; CRUZ, M. C. P.; FERREIRA, M. E. Nutrientes limitantes ao desenvolvimento do capim tifton 85 em argissolo vermelho-amarelo. B. Industr. Anim., N.Odessa, v.63, n.1, p.11-18, 2006

TSUTIYA, M. T.; HIRATA, A.Y. Aproveitamento e disposição final de lodos de estações de tratamento de água do estado de São Paulo. In: CONGRESSO BRASILEIRO DE ENGENHARIA SANITÁRIA E AMBIENTAL, 21.,2001, João Pessoa. Anais. João Pessoa: ABES [CDROM],2001. Disponível em< http://www.bvsde.paho.org/bvsaidis/caliagua/brasil/i-025.pdf >. Acessado em: 19 abr. 2015. 